\title{
A (IN)APLICABILIDADE DO PRINCÍPIO DA ANTERIORIDADE DA LEI TRIBUTÁRIA À NORMA REVOGADORA DE ISENÇÃO FISCAL
}

\author{
THE (NON) APPLICABILITY OF THE \\ TAX LAW ANTERIORITY PRINCIPLE TO \\ THE REPEAL OF TAX EXEMPTION
}

\author{
Matheus Lolli Pazeto ${ }^{1}$
}

Resumo: O presente artigo tem como objetivo debater a aplicabilidade ou não do princípio da anterioridade da lei tributária à norma que revoga uma isenção fiscal. O princípio da anterioridade, como limitação ao poder de tributar, mostra-se importante no Sistema Tributário Nacional para garantir o direito de os contribuintes planejarem seus negócios e atividades. Os benefícios fiscais, entendidos como reduções ou supressões da carga tributária visando a mudança comportamental dos sujeitos passivos, normalmente a fim de fomentar o desenvolvimento econômico, abrangem, dentre eles, a isenção. A isenção é sempre concedida por meio de lei do ente que detém a competência para instituir o tributo, estando alocada no Código Tributário Nacional como causa de exclusão do crédito tributário. Em sede doutrinária, formaram-se, acerca de sua natureza, teorias envolvendo sua incidência nos planos fático e jurídico. A mais clássica entende que isenção é a dispensa legal do pagamento do tributo. Esta teoria tem pautado a corrente que defende a inaplicabilidade do princípio da anterioridade tributária à lei que revogue ou diminua uma isenção, posição que se mostrou tradicional na jurisprudência do STF. Outra teoria sustenta que o preceito isentante tem por fim negar a existência da relação jurídico tributária, atingindo a regra-matriz de incidência tributária. Em recente decisão, o STF promoveu novo entendimento e decidiu pela aplicabilidade do princípio da anterioridade tributária à lei que reduza um benefício fiscal. Esta decisão suscita o debate sobre a adoção de uma outra postura pela Suprema Corte frente ao tema, com a adoção da segunda teoria formulada em torno da natureza da isenção.

1 Bacharel em Direito pela Universidade Federal de Santa Catarina (UFSC). Assessor Jurídico no Tribunal de Justiça do Estado de Santa Catarina (TJSC) no gabinete do Desembargador Marcus Tulio Sartorato. E-mail: matheuslolli@gmail.com 
Palavras-chave: Princípio. Anterioridade tributária. Benefício fiscal. Isenção. Revogação.

Abstract: This article aims to discuss the applicability or not of the principle of the tax law anteriority to the repeal of tax benefit. The principle of the tax law anteriority, as a limitation to tax powing, appears to be important in the national tax system to ensure the right of taxpayers plan their business and activities. The tax benefits, understood as a reduction or elimination of taxes aimed at behavioral change of taxpayers, usually in order to foster economic development, cover, among them, the exemption. The exemption is always granted by the entity law that has the power to impose tribute, being allocated in the tax code as a cause of exclusion of the tax credit. In doctrine, it was formed, about its nature, theories involving its impact on the factual and legal plans. The most classic understands that exemption is the legal exemption from tax payment. This theory has guided the conception that supports the inapplicability of the tax law anteriority to the repeal of tax exemption, idea that proved to be traditional in the Supreme Court jurisprudence. Another theory holds that the exemption is intended to deny the existence of tax legal regard, reaching the tax incidence of rule-matrix. In a recent decision, the Supreme Court held a new understanding and decided to the applicability of the tax law anteriority to the repeal of tax benefit. This decision raises the debate on the adoption of a different approach by the Supreme Court, facing the issue with the adoption of the second theory formulated around the nature of the tax exemption.

Keywords: Principle. Tax law anteriority. Tax benefit. Tax exemption. Repeal.

\section{INTRODUÇÃO}

O princípio da anterioridade da lei tributária, apresentado no texto constitucional dentre as limitações ao poder de tributar, exalta uma grande garantia do contribuinte frente ao Poder Público.

Se não há dúvidas sobre a aplicabilidade deste princípio a uma lei que institua ou majore um tributo, o mesmo não se pode dizer em relação à lei que revogue ou diminua um benefício fiscal.

A isenção, como espécie de benefício fiscal, é apresentado no Código Tributário Nacional como causa de exclusão do crédito tributário, fato que, como se demonstrará ao longo do 
artigo, é insuficiente para definir sua natureza e a repercussão nos planos fático e jurídico.

Em razão disso, teorias se formaram na doutrina para definir a natureza da isenção, se favor legal que dispensa do pagamento do tributo ou preceito que impede a própria incidência tributária.

Ademais, a doutrina também apresenta posições divergentes sobre a aplicabilidade do princípio da anterioridade tributária à norma que revoga ou diminui uma isenção fiscal, por vezes em razão da teoria adotada e interpretação do art. 103 do Código Tributário Nacional.

Essa divergência será abordada ao longo do artigo, inclusive com os reflexos causados na jurisprudência do Supremo Tribunal Federal, sem perder de vista decisão recente da Suprema Corte, a qual pode indicar um novo posicionamento do Tribunal sobre o tema.

\section{O PRINCÍPIO DA ANTERIORIDADE TRIBUTÁRIA}

A Constituição da República Federativa do Brasil de 1988 (CRFB/88), em seu Capítulo que trata do Sistema Tributário Nacional, dispõe, ao longo de toda a Seção II, sobre as limitações do poder de tributar.

Sobre o tema, clássica é a lição de Baleeiro (1997, p. 2):

Nos países de Constituição rígida e de controle judiciário das leis e atos administrativos, os princípios que a Ciência das Finanças apurou em sua compósita formação política, moral econômica ou técnica são integrados em regras estáveis e eficazes. Funcionam como limitações ao poder de tributar.

[...] o sistema tributário movimenta-se sob a complexa aparelhagem de freios e amortecedores, que limitam os excessos acaso detrimentosos à economia e à preservação do 
regime e dos direitos individuais. [...] A defesa do sistema tributário e do próprio regime político do país processa-se por um conjunto de limitações ao poder ativo de tributar.

Conforme também define Amaro (2011, p. 129), a função dessas limitações "[...] é demarcar, delimitar, fixar fronteiras ou limites ao exercício do poder de tributar. São, por conseguinte, instrumentos definidores (ou demarcadores) da competência tributária dos entes políticos no sentido de que concorrem para fixar o que pode ser tributado e como pode sê-lo".

Coêlho (2015, p. 174) discorre sobre a importância do respeito, por parte dos governantes, aos princípios jurídicos delineados na Carta Magna em relação à atividade tributária. Para o autor, três consequências benéficas são oriundas de tal comportamento:

a) assegura aos governados tranquilidade, confiança e certeza quanto à tributação;

b) assegura ao governo o respeito dos governados;

c) compartilha o governo com o parlamento a responsabilidade pelos rumos da política tributária, como sói acontecer nas verdadeiras democracias.

Dentre as limitações constitucionais ao poder de tributar, destaca-se o princípio da anterioridade da lei tributária.

Para Coêlho (2015, p. 173),

[...] o princípio da anterioridade expressa a ideia de que a lei tributária seja conhecida com antecedência, de modo que os contribuintes, pessoas naturais ou jurídicas, saibam com certeza e segurança a que tipo de gravame estarão sujeitas no futuro imediato, podendo, dessa forma, organizar e planejar seus negócios e atividades.

O mencionado princípio está contido no art. 150, inciso III, alíneas "b" e "c" da CRFB/88. Colaciona-se os referidos dispositivos constitucionais:

Art. 150. Sem prejuízo de outras garantias asseguradas ao 
contribuinte, é vedado à União, aos Estados, ao Distrito Federal e aos Municípios:

$[\ldots]$

III-cobrar tributos:

$[\ldots]$

b) no mesmo exercício financeiro em que haja sido publicada a lei que os instituiu ou aumentou;

c) antes de decorridos noventa dias da data em que haja sido publicada a lei que os instituiu ou aumentou, observado o disposto na alínea $b$;

Como se denota do texto constitucional, desde quando haja sido publicada a lei que instituiu ou aumentou o tributo, é vedado aos entes federativos cobrá-lo no mesmo exercício financeiro e antes de decorridos noventa dias.

O que se visualiza, então, é uma dupla faceta do princípio da anterioridade da lei tributária, sempre constituindo freios ao poder de tributar, de modo que não se imponha ao contribuinte um súbito aumento da carga tributária.

Nesse sentido, na seara das definições terminológica, expõe Sabbag (2014, p. 87) que:

[...] a alínea 'b' atrela-se à 'anterioridade anual', também intitulada 'anterioridade de exercício', 'anterioridade comum', ou, como preferem muitos estudiosos, simplesmente, 'anterioridade"". E continua o autor: "A alínea 'c', por sua vez, refere-se à 'anterioridade privilegiada', também reconhecida por 'anterioridade qualificada' ou 'anterioridade nonagesimal.

Ainda em busca da precisa definição do princípio da anterioridade da lei tributária, colaciona-se a diferença realizada por Machado (2015, p. 37) entre o princípio da anterioridade e o princípio da anualidade:

Como se vê, os princípios da anualidade e da anterioridade realmente não se confundem. O princípio da anterioridade quer dizer que nenhum tributo pode ser cobrado sem que a 
lei que o instituiu, ou aumentou, tenha sido publicada antes do início do exercício da cobrança. Um imposto instituído em lei publicada em 2011 somente a partir de 2012 pode ser cobrado. Mas poderá ser cobrado também nos anos seguintes, indefinidamente. O princípio da anualidade é diferente porque, segundo ele, além da lei de criação ou aumento do imposto, há necessidade de previsão da cobrança no orçamento de cada ano. A previsão da cobrança, na lei orçamentária anual, é indispensável.

Dessa forma, o princípio da anterioridade da lei tributária funciona como um direito do contribuinte perante o poder público, a fim de que estejam assegurados seu planejamento e sua organização das atividades.

Esse direito fica ainda mais visível após a decisão do Supremo Tribunal Federal, na ADI 939-MC/DF, que reconheceu a existência de direitos fundamentais ao longo de todo o texto constitucional, e não só nos incisos do art. $5^{\circ}$ da CRFB/88, dentre eles o princípio da anterioridade tributária. Nas exatas palavras do voto vencedor do Ministro Sydney Sanches: "entre esses direitos e garantias individuais, estão, pela extensão contida no $\S 2^{\circ}$ do art. $5^{\circ}$ e pela especificação feita no art. 150 , III, 'b', a garantia do contribuinte de que a União não criará nem cobrará tributos, "no mesmo exercício financeiro em que haja sido publicada a lei que os instituiu ou aumentou".

Importante ressalva sobre o princípio da anterioridade da lei tributária é feita por Alexandre (2015, p. 116), no sentido de que:

[...] o princípio existe para proteger o contribuinte, não impedindo, portanto, a imediata aplicação das mudanças que diminuam a carga tributária a que o contribuinte está sujeito (casos de extinção ou redução dos tributos) ou que não tenham qualquer impacto sobre essa carga tributária.

Portanto, pode-se concluir pela grande relevância do princípio da anterioridade da lei tributária-espécie de limitação ao poder de tributar-como fonte de proteção do contribuinte fren- 
te a eventual súbito aumento dos tributos por parte da fazenda pública, assegurando-se seu direito de planejamento financeiro, o que foi levado pelo Supremo Tribunal Federal à alçada de direito fundamental do indivíduo.

\section{A ISENÇÃO COMO BENEFÍCIO FISCAL}

Antes de ingressar no estudo da aplicação do princípio da anterioridade da lei tributária à revogação da isenção tributária, compete discorrer sobre o regime dos benefícios fiscais e, mais precisamente, sobre a própria isenção.

Conceito de benefícios fiscais é fornecido por Melo (2007, p. 367), para quem:

O Poder Público estabelece situações desonerativas de gravames tributários, mediante a concessão de incentivos e benefícios fiscais, com o natural objetivo de estimular o contribuinte à adoção de determinados comportamentos, tendo como propósito subjacente a realização de diversificados interesses.Qualificam-se como prêmios as imunidades, isenções, reduções de base de cálculo, créditos outorgados, etc., sujeitando-se a um regime jurídico diferenciado (extrafiscalidade), porque representam dispêndio para o Poder Público e benefício para os contribuintes.

Segundo Geraldo Ataliba e José Artur Lima Gonçalves, citados por Vogas (2011, p. 55-56), os incentivos fiscais são mecanismos cujo fim é impulsionar ou atrair os particulares para a realização das atividades que o Estado define como prioritárias, " [...] tornando, por assim dizer, os particulares em participantes e colaboradores da concretização das metas postas como desejáveis a do desenvolvimento econômico e social por meio da ação do comprometimento ao qual são condicionados".

Logo, incentivos fiscais são reduções ou exclusões totais da carga tributária, concedidas pelo ente político detentor de sua capacidade tributária, visando a mudança comportamental dos 
sujeitos passivos, normalmente a fim de fomentar o desenvolvimento econômico e minimizar as desigualdades regionais em seu território.

Importante benefício fiscal presente no Sistema Tributário Nacional é a isenção.

Conforme Carvalho (2016, p. 461):

O mecanismo das isenções é um forte instrumento de extrafiscalidade. Dosando equilibradamente a carga tributária, a autoridade legislativa enfrenta as situações mais agudas, em que vicissitudes da natureza ou problemas econômicos ou sociais fizeram quase desaparecer a capacidade contributiva de certo segmento geográfico ou social. A par disso, fomenta as grandes iniciativas de interesse público e incrementa a produção, o comércio e o consumo, manejando de modo adequado o recurso jurídico das isenções.

A isenção está prevista no Código Tributário Nacional (CTN), localizada no Capítulo que trata da exclusão do crédito tributário, tendo como característica marcante o fato de decorrer de lei que especifique os requisitos exigidos para sua concessão, podendo ser revogada ou modificada a qualquer tempo também por atividade legislativa, o que garante grande potencial de exercício pelos entes federativos de suas competências tributárias.

Além disso, faz-se mister consignar que a isenção é o benefício fiscal que mais deflagra discussões doutrinárias sobre sua incidência no plano fático e jurídico, existindo diversas teses a respeito da natureza do instituto.

Conforme Carvalho (2016, p. 451), "clássica é a tese de que a isenção é um favor legal consubstanciado na dispensa do pagamento do tributo devido". E continua o autor: "essa posição doutrinária teve em Rubens Gomes de Sousa (o principal coautor do Anteprojeto do Código Tributário Nacional) seu grande patrono e, ainda que não tenha sido plasmada no texto, impregnou toda 
a disciplina jurídica da matéria naquele Estatuto".

Tese esta não corroborada por Alfredo Augusto Becker, o qual, segundo mencionado por Carvalho (2016, p. 452), criou a ideia de que "[...] o preceito isentante tem por fim justamente negar a existência da relação jurídica tributária. A regra de isenção incide para que a de tributação não possa incidir".

Todavia, a grande crítica formulada por citado autor sobre as teorias supracitadas é que a isenção não ingressa no plano fático. Consoante suas lições, a norma de isenção ataca a norma-matriz de incidência do tributo, despindo-a parcialmente de um de seus critérios, impedindo que ela possa irradiar seus efeitos no plano fático. Explica o autor:

Guardando a sua autonomia normativa, a regra de isenção investe contra um ou mais dos critérios da norma-padrão de incidência, mutilando-os, parcialmente. É óbvio que não pode haver supressão total do critério, porquanto equivaleria a destruir a regra-matriz, inutilizando-a como norma válida no sistema. O que o preceito da isenção faz é subtrair parcela do campo de abrangência do critério do antecedente ou do consequente. (CARVALHO, 2016, p. 456).

Assim, a isenção é forma de incentivo fiscal composto por técnica legislativa que inibe a operatividade da regra-matriz, de modo que "[...] mesmo acontecendo o evento tributário, no nível da concretude real, não pode o fato ser constituído e seus peculiares efeitos não se irradiam, justamente porque a relação obrigacional não se poderá instalar à míngua de objeto". (CARVALHO, 2016, p. 460).

A título de conclusão do tópico, colaciona-se trecho da doutrina de Paulsen (2013, p. 1214), o qual compila precisamente as principais teorias que surgiram em torno da natureza da isenção e aqui esposadas:

Para Rubens Gomes de Souza, favor legal consubstanciado na dispensa do pagamento do tributo. Para Alfredo 
Augusto Becker e José Souto Maior Borges, hipótese de não incidência da norma tributária. Para Paulo de Barros Carvalho, o preceito de isenção subtrai parcela do campo de abrangência do critério antecedente ou do consequente da norma tributária, paralisando a atuação da regra-matriz de incidência para certos e determinados casos.

Por fim, importante colacionar passagem de Rubens Gomes de Sousa, trazida na obra de Amaro (2011, p. 309), o qual, na condição de um dos idealizadores do texto do atual Código Tributário Nacional, afirmou que aludido código

[...] não tomou partido nessa controvérsia doutrinaria, limitando-se a dispor, no art. 175, n. I, que a isenção exclui o crédito tributário. Isso pode significar que, nos casos de isenção, inexiste a própria obrigação tributária, de vez que o crédito é simples decorrência daquela (art. 139). Ou pode significar que a obrigação tributária existe mas é incobrável, porquanto a obrigação de pagar é inexigível quando inexista o crédito correspondente.

Destarte, verifica-se que a isenção, como espécie de benefício fiscal, apresenta-se como centro de um grande debate teórico, ao passo que entendê-lo pode servir para auxiliar na resolução de problemas práticos, como o sugerido neste artigo.

No tópico derradeiro que segue, passar-se-á a discorrer sobre os posicionamentos em torno da aplicabilidade ou não do princípio da anterioridade da lei tributária, com uma abordagem também da jurisprudência sobre o tema, avaliando, ainda, como as diferentes teorias em torno da isenção podem influenciar nesse processo.

\section{A (IN)APLICABILIDADE DO PRINCÍPIO DA ANTERIORIDADE DA LEI TRIBUTÁRIA À NORMA REVOGADORA DE ISENÇÃO FISCAL}

Como já abordado neste artigo, o princípio da anterioridade da lei tributária é um direito do indivíduo, instituído no texto 
constitucional como limitação ao poder de tributar e previsto no art. 150, III, "b" e "c", da CRFB/88, que permite ao contribuinte organizar e planejar seus negócios e atividades.

Por sua vez, preceitua expressamente o art. 104, III, do CTN:

Entram em vigor no primeiro dia do exercício seguinte àquele em que ocorra a sua publicação os dispositivos de lei, referentes a impostos sobre o patrimônio ou a renda: [...]

III-que extinguem ou reduzem isenções, salvo se a lei dispuser de maneira mais favorável ao contribuinte, e observado o disposto no artigo 178.

Assim, surge a questão sobre a aplicabilidade ou não do princípio da anterioridade ao caso em que há revogação de isenção tributária.

Para uma primeira corrente, a revogação de uma isenção não está sujeita ao princípio da anterioridade tributária.

Nesse sentido, veja-se a posição de Valdir de Oliveira Rocha, em obra coordenada por Martins:

A extinção ou redução de isenções, salvo se a lei dispuser de maneira mais favorável ao contribuinte, e observada a prevalência das concedidas por prazo certo e em função de determinadas condições, não se submetem-como quer o art. 104, III, do CTN-ao princípio da anterioridade do exercício. Aceita-se a disposição do Código Tributário Nacional partindo-se de distinção necessária entre não incidência e isenção: na não incidência dispensa-se, afasta-se, o próprio tributo; na isenção, exclui-se o crédito do tributo (MARTINS, 2011, p. 83).

Denota-se que, para o mencionado autor, a isenção funciona como excludente do crédito tributário, em adoção à clássica posição de Rubens Gomes de Sousa sobre o tema da natureza da isenção, o que leva, portanto, à conclusão de que não haveria necessidade de aplicação do princípio da anterioridade da lei tributária, uma vez que a obrigação tributária nunca foi 
afastada, mas apenas o crédito tributário.

Por muito tempo, esse tem sido o entendimento tradicional do Supremo Tribunal Federal sobre o assunto.

A este respeito, colaciona-se ementa do acórdão da Suprema Corte no Recurso Extraordinário $\mathrm{n}^{\circ} 204.062$, da Segunda Turma, Relator Ministro Carlos Velloso: "Revogada a isenção, o tributo torna-se imediatamente exigível. Em casos assim, não há que se observar o princípio da anterioridade, dado que o tributo já é existente".

Selecionando trechos do voto vencedor, com citação expressa, as razões são bem expostas na obra de Paulsen (2013, p. 875):

Veja-se o voto condutor: "[...] A Corte Suprema tem entendido que, revogada a isenção, o tributo torna-se imediatamente exigível. O 'leading case' foi o RMS no 13.947SP, Relator o Ministro PRADO KELLY, na RTJ 39/64. O acórdão partiu do pressuposto de que a isenção distingue-se da não incidência [...] Está no acórdão líder-RMS 13.947$\mathrm{SP}-q u e$, na isenção, o tributo já existe. Por isso, revogado o favor legal, força é concluir que um novo tributo não foi criado, senão que houve apenas a restauração de direito de cobrar o tributo, o que não implica a obrigatoriedade de ser observado o princípio da anterioridade [...]".

Dessa forma, vislumbra-se uma tendência na jurisprudência tradicional de seguir a posição de que a revogação da isenção não cria uma nova obrigação tributária, apenas restaura o dever de pagamento do crédito tributário anteriormente dispensado, motivo pelo qual não estaria sujeita ao princípio da anterioridade da lei tributária.

E o mesmo entendimento seguiu desde então, a exemplo da seguinte decisão no Agravo Regimento no Recurso Extraordinário $n^{0}$ 562.669, da Primeira Turma, Relator Ministro Ricardo Lewandowski, cuja ementa foi assim redigida:

AGRAVO REGIMENTAL EM RECURSO EXTRAORDI- 
NÁRIO. REVISÃO OU REVOGAÇÃO DE BENEFÍCIO FISCAL. POLÍTICA ECONÔMICA. POSSIBILIDADE DE REVISÃO PELO ESTADO. DESNECESSIDADE DE OBSERVAÇÃO DAS REGRAS DE ANTERIORIDADE TRIBUTÁRIA PREVISTAS NA CONSTITUIÇÃO FEDERAL. AGRAVO IMPROVIDO.

I - A revisão ou revogação de benefício fiscal, por se tratar de questão vinculada à política econômica que pode ser revista pelo Estado a qualquer momento, não está adstrita à observância das regras de anterioridade tributária previstas na Constituição. Precedentes.

II - Agravo regimental improvido.

Em igual sentido, veja-se como decidiu a Suprema Corte, no Recurso Extraordinário no 562.669, também funcionando como relator o Ministro Ricardo Lewandowski, mas agora na Segunda Turma: "a revisão ou revogação de benefício fiscal, por se tratar de questão vinculada à política econômica que pode ser revista pelo Estado a qualquer momento, não está adstrita à observância das regras de anterioridade tributária previstas na Constituição".

Portanto, tem-se como uma primeira corrente a que se orienta pela não aplicabilidade do princípio da anterioridade à lei que revoga um benefício fiscal, a exemplo da isenção, pautada, em suma, na doutrina que entende ser a isenção um favor legal que dispensa o pagamento do tributo.

De outro norte, verifica-se na doutrina um grande número de autores que defendem outra posição, no sentido de que a norma que revoga uma isenção está sujeita ao princípio da anterioridade tributária.

Nesse sentido, conforme Carvalho (2016, p. 464):

É questão assente que os preceitos de lei que extingam ou reduzam isenções só devam entrar em vigor no primeiro dia do exercício seguinte àquele em que forem publicados. Os dispositivos editados com esse fim equivalem, em tudo 
e por tudo, aos que instituem o tributo, inaugurando um tipo de incidência. Nesses termos, em homenagem ao princípio da anterioridade, o termo inicial de sua vigência fica diferido para o primeiro dia do próximo exercício.

Também é a posição de Carrazza (2015, p. 251):

A lei ordinária que extingue ou reduz uma isenção somente poderá ser aplicada no exercício vindouro ao de sua entrada em vigor. A razão disso está em que a lei que afasta ou diminui uma isenção tributária assemelha-se, em tudo e por tudo, à que cria ou aumenta um tributo. Afinal, o encargo que acarreta para o contribuinte é o mesmo. Seu patrimônio será, por igual modo, atingido. Depois, a aptidão para tributar compreende a de isentar, como verso e anverso de idêntica medalha.

Outrossim, leciona Amaro (2011, p. 312) que:

[...] se trata de tributo sujeito ao princípio da anterioridade, é óbvio que a revogação da isenção, tendo o mesmo efeito da edição de regra de tributação, importa em que o tributo só possa ser aplicado a partir do exercício seguinte àquele em que a norma legal seja editada. O Código Tributário Nacional deixou isso expresso no art. 104, III.

O autor ainda tece críticas ao Enunciado nº 615 da Súmula do Supremo Tribunal Federal, in verbis: "o princípio constitucional da anualidade ( $\$ 29$ do art. 153 da CF) não se aplica à revogação de isenção do ICM".

Conforme Amaro (2011, p. 312):

Os fundamentos dessa jurisprudência partem de premissas equivocadas, que, mesmo na hipótese de serem assumidas como corretas, não levariam às conclusões que foram firmadas pelo Supremo. Já alhures procuramos demonstrar que, mesmo quando se admita a consagração, pelo Código Tributário Nacional, do conceito de isenção como "dispensa de tributo devido" (coisa que até Rubens Gomes de Sousa negou, ao dizer que o Código não tomou partido nessa discussão), ainda assim não se pode culpar o Código de ter propiciado oblíquo desrespeito ao princípio da anterioridade na hipótese em exame, pois o seu art. 104, no item III, 
cuidou adequadamente da matéria, quando explicitou que a revogação de isenção de tributo (sujeito à anterioridade) só autoriza a tributação no exercício subsequente. E mesmo que não o dissesse, não se poderia dar ao Código Tributário Nacional interpretação que pudesse ferir, ainda que indiretamente, um princípio constitucional.

Com efeito, o art. 104 do Código Tributário Nacional o que fez foi desdobrar as consequências do princípio da anterioridade [...]. Ao proceder à definição dos efeitos da anterioridade, o preceito foi expresso ao estabelecer que a revogação das isenções se submete àquele princípio. Aquilo que, na época, era aplicável apenas aos tributos sobre a renda e patrimônio hoje deve ser entendido como abrangente de todos os tributos protegidos pelo princípio da anterioridade. Assim, mesmo a revogação de uma isenção de tributo não mencionado no art. 104 submete-se ao princípio da anterioridade, desde que, hoje, esse tributo esteja sujeito a tal princípio.

Logo, percebe-se em parte da doutrina uma inclinação pela teoria de que a norma que revoga outra concedente de isenção se assemelha àquela que cria ou aumenta um tributo, atraindo a incidência do princípio da anterioridade da lei tributária.

Em decisão mais recente do Supremo Tribunal Federal, a Primeira Turma, no Agravo Regimental em Recurso Extraordinário $n^{\circ} 564.225 / \mathrm{RS}$, funcionando como relator o Ministro Marco Aurélio, mudou seu entendimento para considerar aplicável o princípio da anterioridade da lei tributária à revogação de benefício fiscal. Eis a ementa do referido acórdão:

IMPOSTO SOBRE CIRCULAÇÃO DE MERCADORIAS E SERVIÇOS - DECRETOS No 39.596 E No 39.697, DE 1999, DO ESTADO DO RIO GRANDE DO SUL - REVOGAÇÃO DE BENEFÍCIO FISCAL - PRINCÍPIO DA ANTERIORIDADE - DEVER DE OBSERVÂNCIA PRECEDENTES.

Promovido aumento indireto do Imposto Sobre Circulação de Mercadorias e Serviços - ICMS por meio da revogação de benefício fiscal, surge o dever de observância ao princípio da anterioridade, geral e nonagesimal, constante 
das alíneas "b" e "c" do inciso III do artigo 150, da Carta. Precedente - Medida Cautelar na Ação Direta de Inconstitucionalidade $\mathrm{n}^{\mathrm{o}} 2.325 / \mathrm{DF}$, de minha relatoria, julgada em 23 de setembro de 2004.

Veja-se, então, que a decisão mais recente do Supremo Tribunal Federal sobre o assunto é no sentido da necessidade de observância do princípio da anterioridade à norma que reduza um benefício fiscal, por promover um aumento do tributo tal qual a lei que o majore diretamente.

Consoante explica Tróccoli Júnior (2015, p. 109), a respeito das premissas levantadas em tal julgamento, "a primeira premissa é a fixação de um conteúdo teleológico ao princípio da anterioridade: evitar a surpresa com aumentos súbitos do tributo, prejudicando o planejamento fiscal do contribuinte".

Na mesma linha, já destacou Alexandre (2015, p. 120-121) que, no novo julgado, o Supremo Tribunal Federal invocou interpretação teleológica para afirmar que a anterioridade visaria garantir que o contribuinte não fosse surpreendido com o aumento súbito do encargo fiscal.

Logo, denota-se, inicialmente, uma preocupação em assegurar a incidência do princípio da anterioridade tributária sempre que possa haver reflexos patrimoniais ao contribuinte, ainda que a respectiva lei o faça indiretamente. Tal posicionamento vai ao encontro da elevação do mencionado princípio à categoria de direito individual pelo Supremo Tribunal Federal, conforme já exposto aqui.

Ademais, no referido julgado (Agravo Regimental em Recurso Extraordinário no 564.225/RS), o Ministro Roberto Barroso, que acompanhou o relator, assim se manifestou em seu voto, sinalizando para uma possível alteração na jurisprudência da Suprema Corte, inclusive na teoria adotada acerca da natureza da isenção tributária:

6. A ocasião é oportuna para revisitar a jurisprudência da 
Corte, que foi muito bem retratada pela divergência. A concepção de anterioridade que me parece mais adequada é aquela afeta ao conteúdo teleológico da garantia. O princípio busca assegurar a previsibilidade da relação fiscal ao não permitir que o contribuinte seja surpreendido com um aumento súbito do encargo, confirmando o direito inafastável ao planejamento de suas finanças. O prévio conhecimento da carga tributária tem como fundamento a segurança jurídica e como conteúdo a garantia da certeza do direito.

7. Deve ser entendida como majoração do tributo toda alteração ocorrida nos critérios quantitativos do consequente da regra-matriz de incidência. Sob tal perspectiva, um aumento de alíquota ou uma redução de benefício relacionada a base econômica apontam para o mesmo resultado: agravamento do encargo. O que não é a diminuição da redução da base de cálculo senão seu próprio aumento com relação à situação anterior.

Como se percebe do excerto mencionado, o Ministro Roberto Barroso, ao tratar da isenção, já passou a discorrer sobre a regra-matriz de incidência, teoria adotada por Paulo de Barros Carvalho também quando aborda a natureza da isenção, em contrapartida àquela teoria de Rubens Gomes de Sousa que fundamentou parte das decisões da Suprema Corte no sentido oposto.

Em virtude disso, pode-se cogitar uma alteração nos próximos julgados do Supremo Tribunal Federal, o qual pode passar a adotar a segunda corrente aqui tratada neste tópico do artigo, em parte com base na mudança de entendimento em torno da natureza da isenção tributária e seu reflexo na aplicação do princípio da anterioridade tributária.

Portanto, tem-se expostas as duas correntes que rodeiam a aplicabilidade do princípio da anterioridade tributária à norma revogadora de isenção fiscal, devendo-se aguardar qual será a recepção dessa nova decisão do Supremo Tribunal Federal, inicialmente no âmbito da própria Corte, mas também na jurisprudência dos demais tribunais pátrios. 


\section{CONCLUSÃO}

Este artigo procurou debater sobre a aplicabilidade ou não do princípio da anterioridade da lei tributária à norma que revoga ou diminui uma isenção fiscal.

De início, discorreu sobre o próprio princípio da anterioridade da lei tributária, hipótese em que se mostrou estar o princípio inserido no texto constitucional dentre as limitações ao poder de tributar, funcionando como uma importante garantia do contribuinte para planejar seus negócios e atividades. Inclusive, neste ponto foi apontada decisão do Supremo Tribunal Federal que considerou tal princípio como direito fundamental.

Passando à análise da isenção, demonstrou-se sua qualidade de benefício fiscal, operando reduções ou supressões da carga tributária por meio de lei do ente que detém a respectiva competência tributária.

Análise importante foi realizada em torno da natureza da própria natureza jurídica da isenção. Alocada no Código Tributário Nacional como causa de exclusão do crédito tributário, em sede doutrinária se formaram algumas teorias acerca de sua incidência nos planos fático e jurídico.

Neste ponto, foi abordada inicialmente a teoria formulada por Rubens Gomes de Sousa, já clássica no direito tributário, o qual entende que isenção é a dispensa legal do pagamento do tributo. Como se viu, esta teoria tem sido utilizada pela corrente que defende a inaplicabilidade do princípio da anterioridade tributária à lei que revogue ou diminua uma isenção, uma vez que, pela isenção, não se modifica a existência da relação tributária, afastando-se apenas o pagamento do crédito tributário. Esta posição tornou-se tradicional na jurisprudência do STF, conforme se ilustrou com julgados desde a Constituição passada. O principal fundamento utilizado era de que a lei que revoga a isenção não cria um novo tributo, o qual já existia, 
apenas não era exigido.

Conforme se elucidou, outra teoria, agora capitaneada por Paulo de Barros Carvalho, sustenta que o preceito isentante tem por fim negar a existência da relação jurídico tributária, atingindo a regra-matriz de incidência tributária.

Enfim, em recente decisão, o Supremo Tribunal Federal promoveu novo entendimento e decidiu pela aplicabilidade do princípio da anterioridade tributária à lei que reduza um benefício fiscal. O principal fundamento girou em torno da finalidade do princípio da anterioridade tributária, como direito fundamental do contribuinte, mas esta decisão, conforme votos lançados no acórdão, também suscitou o debate sobre a adoção de uma outra postura pela Suprema Corte frente ao tema, com eventual adoção da segunda teoria formulada em torno da natureza da isenção.

Portanto, conclui-se que existem dois posicionamentos em torno da aplicabilidade ou não do princípio da anterioridade da lei tributária à norma que revoga ou diminui uma isenção tributária, divergência que agora se instaurou também no âmbito da jurisprudência, em especial do Supremo Tribunal Federal, e que permeia as teorias formuladas em torno da natureza da isenção, podendo acarretar uma mudança na jurisprudência da Suprema Corte, ou a retomada daquela já tradicional, a depender da adoção de uma ou outra corrente.

\section{REFERÊNCIAS}

ALEXANDRE, Ricardo. Direito tributário esquematizado. 9. ed. rev., atual. e ampl. Rio de Janeiro: Forense; São Paulo: Método, 2015.

AMARO, Luciano. Direito tributário brasileiro. 17. ed. São Paulo: Saraiva, 2011.

BALEEIRO, Aliomar. Limitações constitucionais ao poder de tributar. 7. ed. rev. e compl. à luz da Constituição de 1988 até a Emenda Constitucional no 10/1996. Rio de Janeiro: Forense, 1999. 
BRASIL. Constituição da República Federativa do Brasil. Brasília: Congresso Nacional, 1988. Disponível em: <http://www.planalto.gov.br/ccivil_03/Constituicao/Constituicao.htm>. Acesso em: 13 jun. 2016.

. Lei $n^{\circ}$ 5.172, de 25 de outubro de 1966. Brasília: Congresso Nacional, 1966. Disponível em:<http://www.planalto.gov.br/ccivil_03/leis/L5172Compilado.htm> Acesso em: 13 jun. 2016.

. Supremo Tribunal Federal. Ação direta de inconstitucionalidade n 939-MC/ $\overline{D F}$. Requerente: Confederação Nacional dos Trabalhadores no Comércio. Relator: Ministro Sydney Sanches. Órgão Julgador: Tribunal Pleno. Brasília, 17 de dezembro de 1993. Disponível em: $<$ http://www.stf.jus.br> Acesso em: 13 jun. 2016.

. Supremo Tribunal Federal. Agravo Regimental no Recurso Extraordinário $n^{o}$ 562.669/MG. Agravante: Curvel Curvelo Veículos Ltda. Relator: Ministro Ricardo Lewandowski. Órgão Julgador: Primeira Turma. Brasília, 19 de maio de 2011. Disponível em: $<$ http://www.stf.jus.br> Acesso em: 14 jun. 2016.

Supremo Tribunal Federal. Agravo Regimental no Recurso Extraordinário $\overline{n^{\circ}}$ 564.225/RS. Agravante: Estado do Rio Grande do Sul. Relator: Ministro Marco Aurélio. Órgão Julgador: Primeira Turma. Brasília, 18 de novembro de 2014. Disponível em: $<$ http://www.stf.jus.br> Acesso em: 14 jun. 2016.

. Supremo Tribunal Federal. Agravo Regimental no Recurso Extraordinário $n^{\circ}$ 617.389/SP. Agravante: Cargill Agrícola S/A. Relator: Ministro Ricardo Lewandowski. Órgão Julgador: Segunda Turma. Brasília, 22 de maio de 2012. Disponível em: $<$ http://www.stf.jus.br> Acesso em: 14 jun. 2016.

. Supremo Tribunal Federal. Recurso Extraordinário $n^{\circ}$ 204.062/ES. Recorrente: Município de Vitória. Relator: Ministro Carlos Velloso. Órgão Julgador: Segunda Turma. Brasília, 19 de dezembro de 1996. Disponível em:<http://www.stf.jus.br> Acesso em: 14 jun. 2016.

. Supremo Tribunal Federal. Súmula $n^{\circ}$ 615. Brasília, 29 de outubro de 1984. Disponível em: $<$ http://www.stf.jus.br $>$ Acesso em: 14 jun. 2016.

CARRAZZA, Roque Antonio. Curso de direito constitucional tributário. 30. ed. rev., ampl. e atual. até a Emenda Constitucional n. 84/2014. São Paulo: Malheiros, 2014.

CARVALHO, Paulo de Barros. Curso de direito tributário. 27. ed. São Paulo: Saraiva, 2016.

COÊLHO, Sacha Calmon Navarro. Curso de direito tributário brasileiro. 14. ed. rev. e atual. Rio de Janeiro: Forense, 2015.

MACHADO, Hugo de Brito. Curso de direito tributário. 36. ed. rev. e atual. São Paulo: Malheiros, 2015.

MARTINS, Ives Gandra da Silva (Coord.). Comentários ao código tributário nacional, volume 2: (arts. 96 a 218). 6. ed. São Paulo, Saraiva, 2011.

MELO, José Eduardo Soares de. Curso de direito tributário. 7. ed. rev. e atual. São Paulo: Dialética, 2007.

PAULSEN, Leandro. Direito tributário: Constituição e código tributário à luz da doutrina e da jurisprudência. 15. ed. Porto Alegre: Livraria do Advogado Editora; ESMA- 
FE, 2013.

SABBAG, Eduardo. Manual de direito tributário. 6. ed. São Paulo: Saraiva, 2014.

TRÓCCOLI JÚNIOR, Henrique. Aplicação do princípio da anterioridade à revogação de benefício fiscal: uma guinada na jurisprudência do Supremo Tribunal Federal? Revista de Estudos Tributários, Porto Alegre, v.18, n.106, p. 99-112, nov./dez. 2015.

VOGAS, Rosíris Paula Cerizze. Limites constitucionais à glosa de créditos de ICMS em um cenário de guerra fiscal. Belo Horizonte: Del Rey, 2011.

Artigo recebido em 16/06/2016

Artigo aprovado em 29/07/2016 